\title{
Genomic Landscapes of Acral Melanomas in East Asia
}

\author{
JOHN WEN-CHENG CHANG ${ }^{1,2}$, JIA-JUAN HSIEH ${ }^{1}$, CHIAO-EN WU $^{1}$, ABNER HERBERT LIM $^{3,4}$, \\ CEDRIC CHUAN-YOUNG NG ${ }^{3,4}$, BIN TEAN TEH ${ }^{4,5}$ and JASON YONGSHENG CHAN ${ }^{5,6}$ \\ ${ }^{1}$ Division of Hematology-Oncology, Department of Internal Medicine, Chang Gung Memorial Hospital at Linkou, \\ Chang Gung University College of Medicine, Taoyuan, Taiwan, R.O.C.; \\ ${ }^{2}$ Immuno-Oncology Center of Excellence, Chang Gung Memorial Hospital at Linkou, Taoyuan, Taiwan, R.O.C.; \\ ${ }^{3}$ Integrated Genomics Platform, National Cancer Centre, Singapore, Singapore; \\ ${ }^{4}$ Laboratory of Cancer Epigenome, National Cancer Centre, Singapore, Singapore; \\ ${ }^{5}$ Oncology Academic Clinical Program, Duke-NUS Medical School, Singapore, Singapore; \\ ${ }^{6}$ Division of Medical Oncology, National Cancer Centre, Singapore, Singapore
}

\begin{abstract}
Background/Aim: Acral melanomas (AM) represent a rare subgroup of melanomas with poor clinical outcomes and are enriched in Asian populations. Recent advances in next generation sequencing have provided opportunities to apply precision medicine to AM. Patients and Methods: Here, we present a series of 13 patients with melanomas from Taiwan and Singapore, including 8 patients with AM profiled using whole exome sequencing and summarize the recent studies on the genomic landscape of AM. Results: We identified mutually exclusive mutations in BRAF, NRAS, HRAS, NFI and KIT in 6 $A M$ cases. In addition, recurrent copy number gains in CCNDI and CDK4, as well as recurrent deletions in $C D K N 2 A / C D K N 2 B, A T M$ and RAD51 were observed, supporting the potential use of CDK4/6 or PARP inhibitors in the treatment of these patients. Conclusion: The genomic landscape of AM provides an important resource for applying novel targeted therapies in this rare disease.
\end{abstract}

Acral melanomas (AM) are a subset of melanomas that arise from non-hair bearing glabrous skin on the palms and soles, or on the nail apparatus (1). Despite global rarity, AM is the

This article is freely accessible online.

Correspondence to: Dr. John Wen-Cheng Chang, Division of Hematology-Oncology, Department of Internal Medicine, Chang Gung Memorial Hospital at Linkou, Chang Gung University College of Medicine, Taoyuan, Taiwan, R.O.C. Tel: +886 33281200, e-mail: wen1902@ hotmail.com; Dr. Jason Yongsheng Chan, Division of Medical Oncology, National Cancer Centre Singapore, 11 Hospital Dr, 169610 Singapore, Singapore. Tel: +65 64368000, Fax: +65 62256283, e-mail: jason.chan.y.s@ nccs.com.sg

Key Words: Genomics, precision oncology, rare cancers, targeted therapy. commonest subtype of melanoma in Asian populations (2). Notably, patients with AM harbor worse prognosis as compared with cutaneous melanomas, and survival outcomes remain dismal despite modern advances in the therapeutic landscape of melanomas $(3,4)$.

Recently, next generation sequencing (NGS) technologies, involving whole exome (WES) (5-7) or genome sequencing (WGS) (8-14), have enhanced the molecular understanding of AM. At the molecular level, AM is a distinct disease as compared with cutaneous melanomas, defined by few point or indel mutations and high degrees of complex structural rearrangements and focal copy number alterations (8-10). Unlike cutaneous melanomas, the tumor mutation burden (TMB) is consequently lower and mutational signatures of ultraviolet damage are infrequent (11). At the individual gene level, hotspot mutations in BRAF and NRAS occur in over $50 \%$ of cutaneous melanomas, whereas their occurrence in AM is considerably lower (approximately 10-25\%). On the other hand, mutations in NF1 and KIT, as well as oncogenic amplification of genes such as CCND1, CDK4, and TERT have been demonstrated to be common events in $\operatorname{AM}(5,8)$. These unique genomic alterations harbor therapeutic implications - small molecule inhibitors of KIT and other tyrosine kinases, including imatinib, nilotinib and dasatinib, have demonstrated significant (albeit modest) efficacy against KIT-mutant AM (15-18). Similarly, CDK4/6 inhibitors have also shown promising activity in AM (19). Taken together, the unique genomic landscape of AM offers an opportunity for the application of precision medicine in this rare disease and warrants further investigation.

In this article, we present a series of patients with AM from Taiwan and Singapore profiled using whole exome sequencing and summarize the recent studies on the genomic landscape of AM using NGS, extending our current understanding of this Asian-prevalent subtype of melanoma. 
Table I. Characteristics of the patients included in the study.

\begin{tabular}{|c|c|c|c|c|c|c|}
\hline Patient ID & Subtype & Primary Site & Age at diagnosis & Gender & Country of origin & Stage at diagnosis \\
\hline Mel-01 & Acral lentiginous & Left sole & 85 & Male & Taiwan & IIC \\
\hline Mel-02 & Acral lentiginous & Left big toe & 78 & Male & Taiwan & II \\
\hline Mel-03 & Acral lentiginous & Left foot & 65 & Male & Taiwan & II \\
\hline Mel-04 & Acral lentiginous & Right sole & 60 & Male & Taiwan & IIIC \\
\hline Mel-05 & Acral, nodular pattern & Right big toe & 97 & Male & Singapore & IIC \\
\hline Mel-06 & Acral lentiginous & Right heel & 56 & Male & Singapore & IIIC \\
\hline Mel-07 & Acral, unspecified pattern & Left foot & 51 & Female & Singapore & IIIC \\
\hline Mel-08 & Acral, nodular pattern & Right sole & 61 & Male & Singapore & IIIC \\
\hline Mel-09 & Mucosal & Nasopharynx & 41 & Female & Singapore & IIC \\
\hline Mel-10 & Mucosal & Anus & 75 & Female & Singapore & IIIC \\
\hline Mel-11 & Mucosal & Vagina & 44 & Female & Singapore & IIC \\
\hline Mel-12 & Cutaneous, unspecified pattern & Chest wall & 39 & Male & Singapore & IIIB \\
\hline Mel-13 & Cutaneous, nodular pattern & Left upper arm & 80 & Male & Singapore & IIC \\
\hline
\end{tabular}

\section{Patients and Methods}

Study design and participants. A total of 13 patients with histologically-proven melanoma from the National Cancer Centre Singapore (Singapore) and Chang Gung Memorial Hospital at Linkou (Taiwan, R.O.C.) were included in the study. Clinical information collected included sex, age, stage at diagnosis (20) and primary tumor location. Written informed consent was obtained in accordance with the Declaration of Helsinki. The study was approved by the Institutional Review Boards of all participating hospitals. All authors had access to the study data and had reviewed and approved the final manuscript.

Whole exome sequencing. Genomic DNA isolated from formalinfixed paraffin-embedded or snap frozen tissue with adequate tumor content, as well as from their paired normal tissue, were selected for whole exome sequencing. A qualified pathologist provided the initial microscopic evaluation and assessment of tumor content. Whole exome sequencing was performed with hybrid selection using the Human All Exon kit SureSelect Target Enrichment System (Agilent Technologies, Santa Clara, CA, USA) version 6 and sequenced on the Illumina HiSeq X platform (Illumina, San Diego, CA, USA) as paired-end 150-base pair reads. Read pairs were aligned to the human reference genome NCBI GRC Build 37 (hg19) using Burrows-Wheeler Aligner (BWA MEM) (Wellcome Genome Campus, Hinxton, Cambridge, UK) (21). Optical duplicates were marked with Picard followed by base score recalibration using GATK version 4.1.4 (Broad Institute, Cambridge, MA, USA) for post alignment data processing (22). Somatic variants from the resulting normal and tumor BAM files were identified using Mutect2, and subsequently annotated and prioritized using VEP (Wellcome Genome Campus, Hinxton, Cambridge, UK) (23). Tumor mutation burden was estimated based on the proportion of nonsynonymous variants over the region of interest (ROI) of the exome panel used. Mutational signature identification was performed using SigProfiler Bioinformatics Tools (Wellcome Genome Campus, Hinxton, Cambridge, UK) (24). Biologically significant copy number changes were identified with GISTIC 2.0 (Broad Institute, Cambridge, MA, USA) and copy-number segmentations were processed with TitanCNA v1.17.1 (University of British Columbia, Vancouver, Canada) $(25,26)$.

Literature review criteria. Literature review was performed by searching the PubMed database for articles published from 2010 to 2020. Only articles published in English were considered. Search terms included "acral melanoma" and "genomics". Full articles were retrieved, and further information was obtained from relevant references. We focused on relevant primary articles rather than reviews to compile this review. Final inclusion criteria included studies profiling AM using whole exome sequencing and/or whole genome sequencing. Case reports, commentaries, review articles, meta-analyses were excluded.

\section{Results}

Patient demographics. A total of 13 patients were included in the study based on tissue availability (Singapore cases, $\mathrm{n}=9$; Taiwan cases, $\mathrm{n}=4$ ). The median age was 61 years (range $=39-97$ years) and there was a male predominance $(n=9 ; 69.2 \%)$. Eight cases were acral melanomas, all arising from the feet. Three were mucosal melanomas of the nasopharynx, anus and vagina. Two cases of cutaneous melanomas arising from the chest wall and upper arm were also included for comparison. None of the patients had distant metastases at diagnosis. Table I summarizes the clinical characteristics of all patients in the study cohort.

Somatic mutational landscape and COSMIC mutational signatures. We performed whole exome sequencing of all 13 melanomas with matched non-tumor tissues. Tumor samples were sequenced to a median coverage of $134 \mathrm{X}$ (range $=100 \mathrm{X}$ 270X) and normal samples to a median coverage of $89 \mathrm{X}$ (range $=50 \mathrm{X}-100 \mathrm{X})$. The median tumor mutational burden was 1.1 mutations per megabase (range=0.4-75.6). We identified a total of 919 somatic exonic mutations, including 


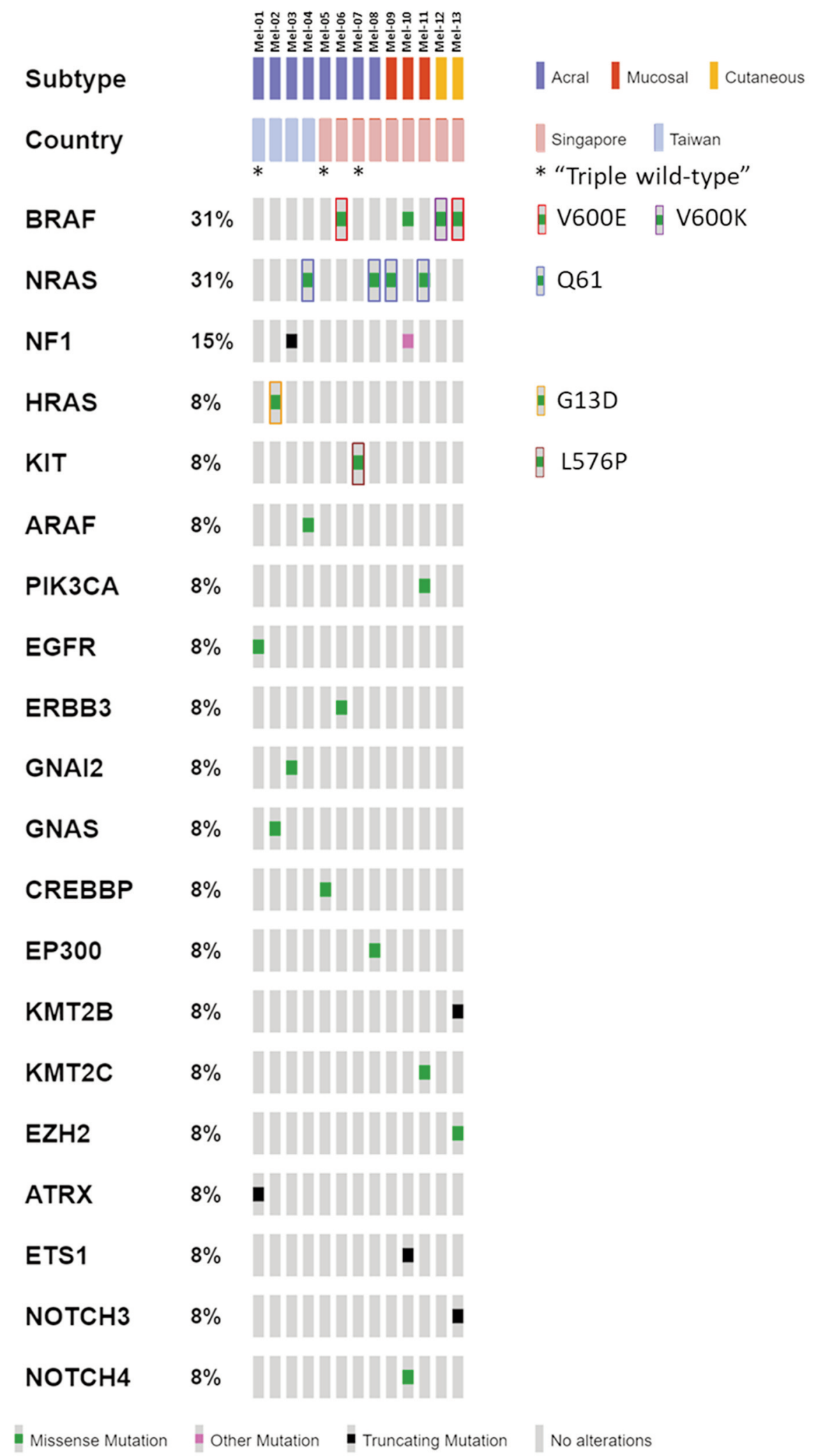

Figure 1. Somatic mutation landscape of acral, mucosal and cutaneous melanoma of East Asian origin. Variants of interest are represented in an oncoplot, including recurrent mutations in genes such as BRAF, NRAS and NF1. Three of 11 non-cutaneous melanomas were "triple wild-type" one of which was characterized by a KIT exon 11 L576P mutation. 


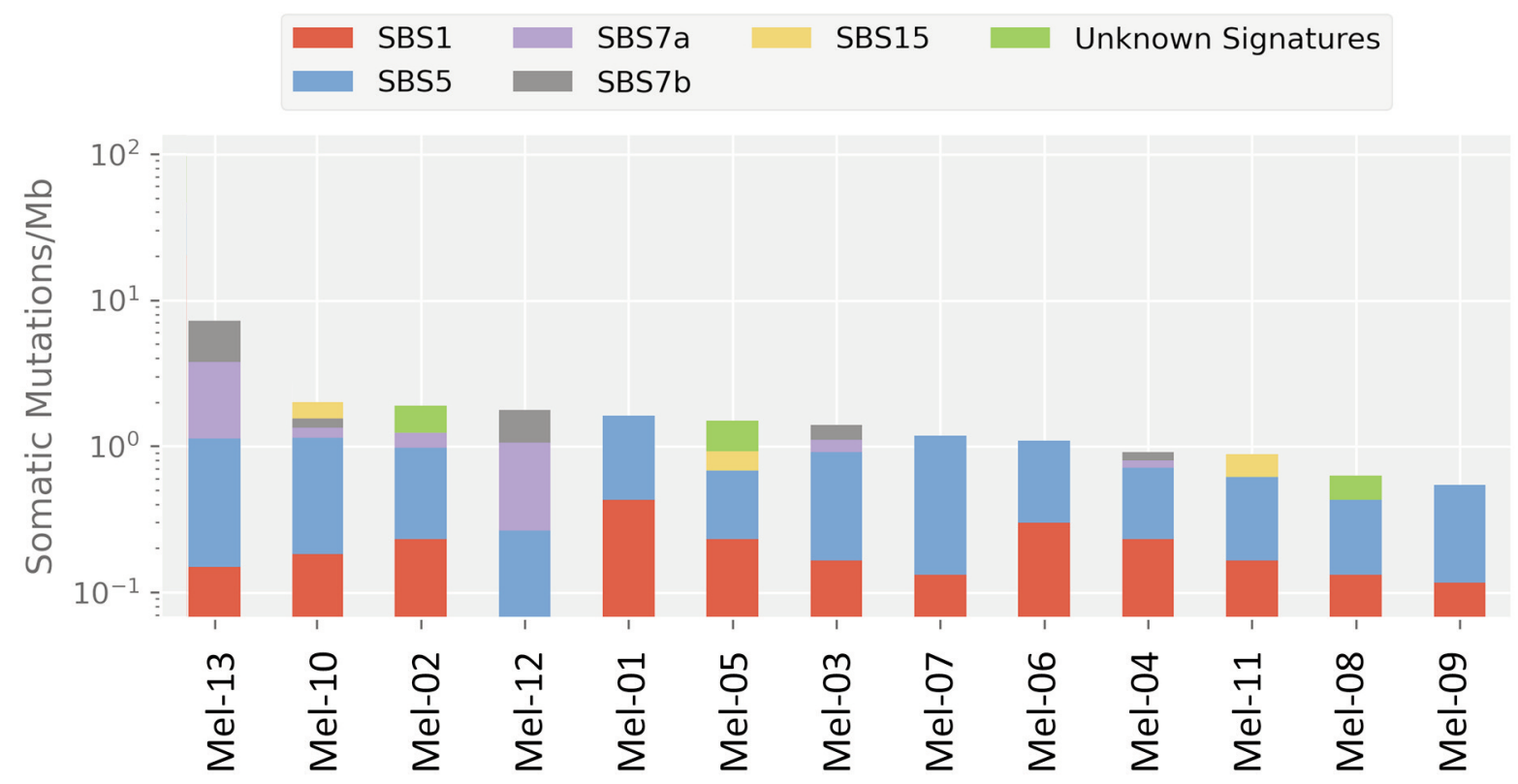

Figure 2. Mutational signatures of melanomas in the cohort. The proportions of mutations conferred by each inferred mutational signature in individual cases are as shown.

\section{Recurrent focal copy-number alterations}
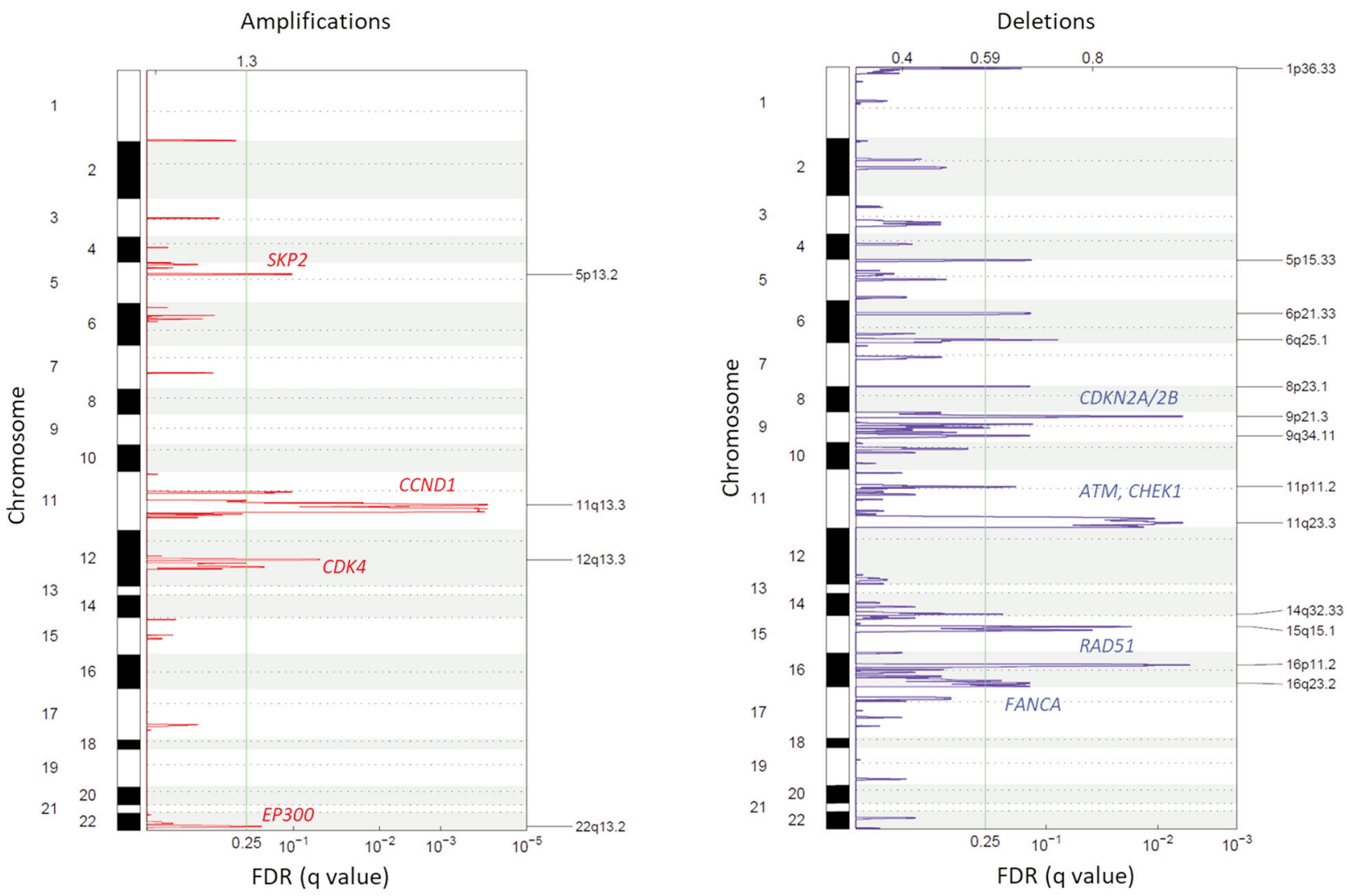

Figure 3. Copy number alterations in the global melanoma cohort. Analysis of somatic copy number alterations identified 4 gained and 13 lost genomic regions. The involved regions and important cancer-related genes within are highlighted. 
Table II. Overview of studies on the genomic landscape of acral melanoma.

\begin{tabular}{|c|c|c|c|}
\hline Reference & Platform & $\mathrm{n}$ & Main findings \\
\hline Newell et al. (8) & $\begin{array}{l}\text { WGS } \\
\text { RNAseq }\end{array}$ & 87 & $\begin{array}{l}\text { - Subset of cases (mostly subungual) harbor ultraviolet mutational signatures } \\
\text { - Whole genome duplication, aneuploidy and complex rearrangements } \\
\text { - Amplification of } T E R T, C D K 4, M D M 2, C C N D 1, P A K 1 \text { and } G A B 2\end{array}$ \\
\hline Hadi et al. (9) & WGS & 35 & $\begin{array}{l}\text { - Complex rearrangement involving amplified fold-back inversions ("Tyfonas") } \\
\text { commonly observed in AM }\end{array}$ \\
\hline $\begin{array}{l}\text { Pan-Cancer Analysis of } \\
\text { Whole Genomes } \\
\text { Consortium (10) }\end{array}$ & WGS & 20 & $\begin{array}{l}\text { - Chromotripsis and kataegis frequent, and commonly co-occur with } \\
\text { gene amplification (CCND1,TERT) }\end{array}$ \\
\hline Hayward et al.(11) & WGS & 35 & $\begin{array}{l}\text { - Genome dominated by structural variations } \\
\text { - Significant mutations include } B R A F, N R A S, N F 1, K I T, M A P 2 K 2 \\
\text { - } 18 \text {-fold fewer mutations than cutaneous melanomas }\end{array}$ \\
\hline Liang et al. (12) & $\begin{array}{l}\text { WGS/WES } \\
\text { RNAseq }\end{array}$ & 34 & $\begin{array}{l}\text { - Somatic alterations dominated by structural variations } \\
\text { - Only } 38 \% \text { harbor } B R A F, N R A S \text { or } N F 1 \text { mutations } \\
\text { - Somatic TERT alterations present in } 41 \% \text { of cases }\end{array}$ \\
\hline Rawson et al. (13) & WGS & 35 & $\begin{array}{l}\text { - } 3 \text { cases harbored ultraviolet mutational signatures (mostly subungual), } \\
\text { and were associated with younger age and higher mutational load }\end{array}$ \\
\hline Furney et al. (14) & WGS & 5 & $\begin{array}{l}\text { - Early work demonstrating fewer mutations but more frequent structural } \\
\text { variations than cutaneous melanomas }\end{array}$ \\
\hline Forschner et al. (5) & WES & 31 & $\begin{array}{l}\text { - Somatic mutations in NF1 (18\%), NRAS (18\%), BRAF (7\%), KIT (11\%) } \\
\text { - Amplification of MYC, TERT, CCND3, RICTOR and CDK4 } \\
\text { - Deletions of CDKN2A/2B, PTEN }\end{array}$ \\
\hline Lee et al. (6) & WES & 2 & - Missense mutations $B R A F \mathrm{~V} 600 \mathrm{E}$ and $N R A S$ Q61R in 2 cases \\
\hline
\end{tabular}

614 missense single nucleotide variants ( $\mathrm{SNVs}$ ), 37 nonsense SNVs, 25 indels and 243 silent mutants. Somatic nonsynonymous variants of interest are represented in an oncoplot, including recurrent mutations in known melanomaassociated genes such as BRAF (31\%), NRAS (31\%), NF1 $(15 \%)$ and $H R A S(8 \%)$ (Figure 1). BRAF mutations were all missense and present in 1 of 8 AM cases (p.V600E), 1 of 3 mucosal melanomas (p.G534R), and both cutaneous melanomas (p.V600E and p.V600K). NRAS mutations were all missense in the p.Q61 hotspot for 2 of 8 AM cases and 2 of 3 mucosal melanoma cases. Notably, 3 of 11 (27.3\%) noncutaneous melanomas were "triple wild-type" - one of which was a KIT exon 11 L576P mutant.

The estimated proportions of mutations contributed by inferred mutational signatures in individual melanoma cases were examined. Signatures 1 and 5, which are related to aging and observed in most cancer types, were present in most of the cases. The signatures for ultraviolet DNA mutagenesis - Single Base Substitution (SBS) 7a and SBS $7 \mathrm{~b}$, as characterized by a majority of $\mathrm{C}>\mathrm{T}$ mutations, were observed in 6 cases ( 2 cutaneous, 1 mucosal, and 3 acral melanomas), though the relative contribution per case was minor (Figure 2).

Somatic copy number alterations. Analysis of somatic copy number alterations identified 4 gained genomic regions (5p13.2, 11q13.3, 12q13.3, 22q13.2). We further identified
13 deleted regions $(1 \mathrm{p} 36.33,5 \mathrm{p} 15.33,6 \mathrm{p} 21.33,6 \mathrm{q} 25.1$, 8p23.1, 9p21.3, 9q34.11, 11p11.2, 11q23.3, 14q32.33, $15 \mathrm{q} 15.1,16 \mathrm{p} 11.2,16 \mathrm{q} 23.2$ ) (Figure 3). Further introspection of individual cases revealed several important gained regions of interest, including chromosome $11 \mathrm{q}$ and $12 \mathrm{q}-$ containing oncogenes CCNDI and CDK4, respectively (Figure 4). Gene-level copy number analysis revealed recurrent copy number gains/amplifications in CCND1 (46\%), CDK4 (31\%), SKP2 (15\%) and EP300 (15\%), and recurrent deletions in CDKN2A/CDKN2B (54\%), ATM (38\%), RAD51 $(38 \%)$ and FANCA (15\%) (Figure 5).

Recent genomic studies on acral melanoma. A total of 92 articles were screened. After excluding review articles $(n=9)$, meta-analyses $(n=1)$, case reports $(n=4)$, commentaries $(n=5)$ and other studies $(n=63), 10$ articles remained and were included in the final analysis. The study design and main findings are summarized in Table II.

\section{Discussion}

Newell et al. have recently reported the largest series of AM profiled using whole genome sequencing $(n=87)$. The authors observed several significantly mutated genes including BRAF, NRAS, NF1, NOTCH2, PTEN and TYRP1, as well as $K I T$ alterations. Mutational signature analysis revealed a subset of tumors, mostly subungual, with an 

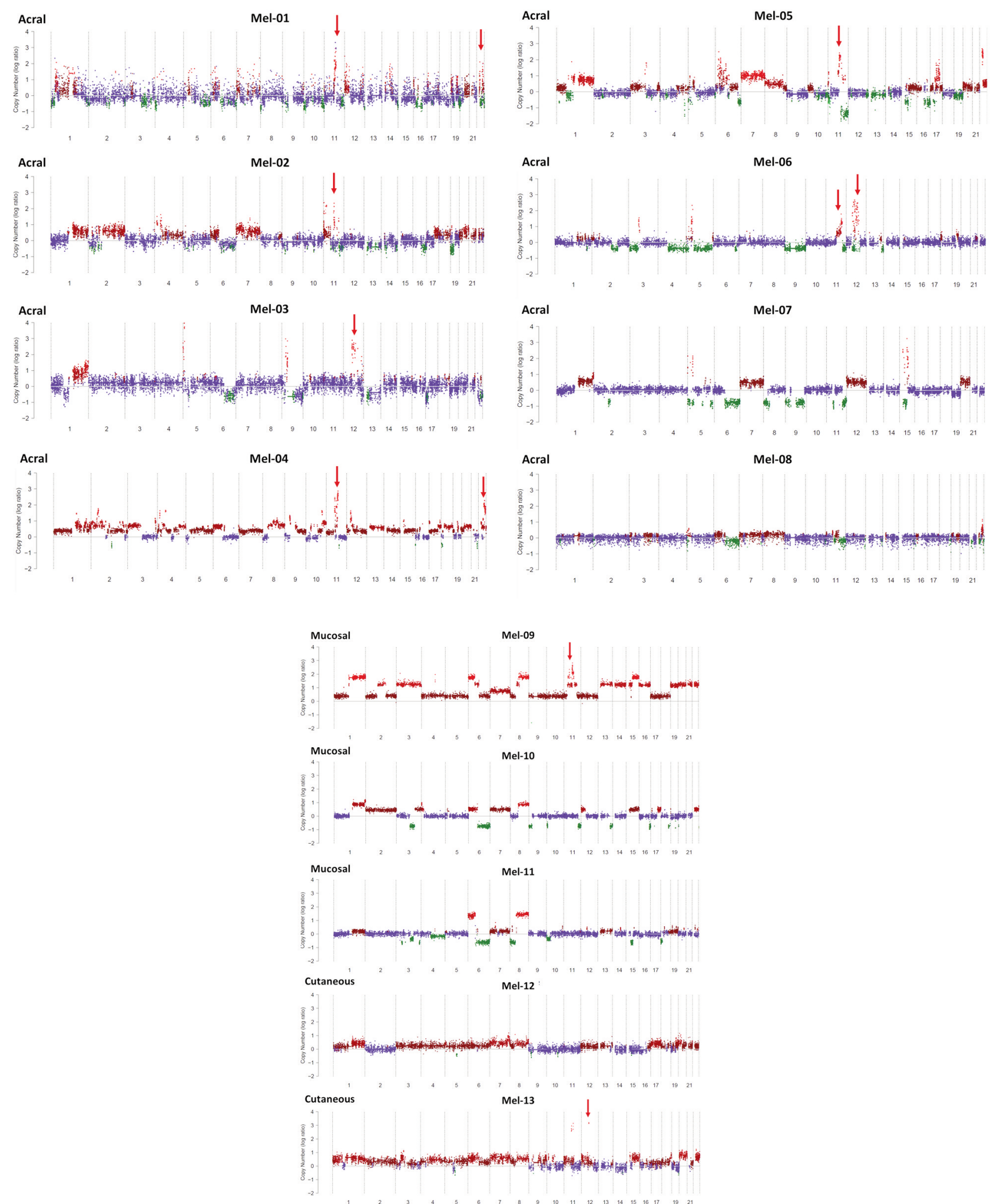

Figure 4. Copy number landscape of individual melanoma cases. Red arrows mark selected gained regions of interest, including chromosome 11q and $12 q$ - containing oncogenes CCND1 and CDK4, respectively. 


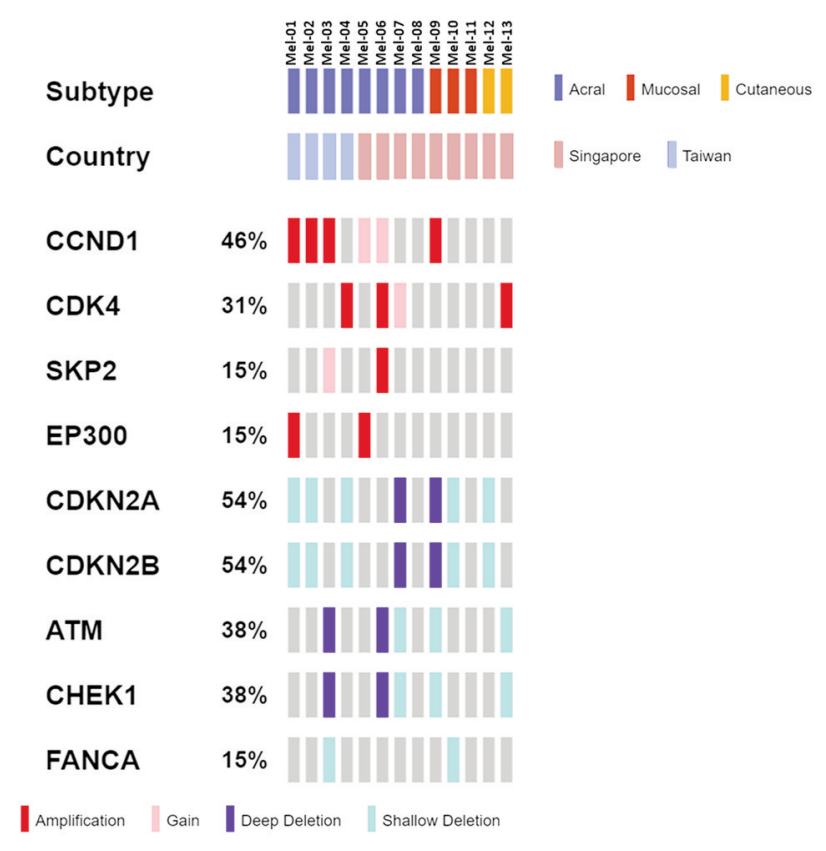

Figure 5. Genomic gains and amplifications of CCND1/CDK4, as well as deletions of CDKN2A/CDKN2B are the commonest copy number alterations. Additionally, deletions of genes involved in DNA damage repair including ATM, RAD51 and FANCA are also frequently observed.

ultraviolet radiation signature. Recurrent complex rearrangements were observed on chromosomes 5, 6, 7, 11 and 12, associated with amplification of TERT, CDK4, $M D M 2, C C N D 1, P A K 1$ and $G A B 2$. In keeping with previous reports $(11,12)$, structural alterations including whole genome duplication, aneuploidy and complex rearrangements (such as breakage-fusion-bridge and chromotripsis) are common in AM (8). A unique form of complex rearrangement involving amplified fold-back inversions, termed "Tyfonas", were commonly observed in AM (40\%) but rarely seen in cutaneous melanomas, and it has been hypothesized that they provide an alternative source of neoantigens through the generation of expressed proteincoding fusions (9). By analyzing SNVs, regions of CCND1 amplification were found to harbor low or even no mutations at a high variant allele fraction in AM. This is in contrast to cutaneous melanomas, in which a large number of mutations typically pre-date amplification and are thus present at a high variant allele fraction. This suggests that both chromothripsis and subsequent gene amplification occur early in the evolution of AM (10).

In the present study, we examined the genomic landscape of AM derived from 2 East Asian countries (Taiwan and Singapore), and also included mucosal and cutaneous melanoma cases for comparison. In the AM cases, somatic nonsynonymous variants in known melanoma-associated genes were present in a mutually-exclusive manner, including BRAF V600E $(\mathrm{n}=1)$, NRAS Q61 $(\mathrm{n}=2), H R A S$ G13D $(\mathrm{n}=1)$ and NF1 $(\mathrm{n}=1)$. Three of the AM cases were "triple wild-type" - one of which harbored a KIT exon 11 L576P mutant. This KIT mutation has been previously reported to confer sensitivity to imatinib (27). In terms of mutational signatures, signatures 1 and/or 5 were present in all cases of AM, which is consistent with previous analyses (8). Signatures for ultraviolet mutagenesis, though present in 3 cases, were not the predominant contributor of the mutations, in keeping with prior observations that ultraviolet signatures, if present, are more likely to contribute to AMs of subungual origin $(8,13)$. In addition to these observations, nearly all cases of AM in our cohort harbored $C C N D 1$ or $C D K 4$ amplification, and or $C D K N 2 A / 2 B$ deletion. Interestingly 2 of the cases contained deep deletions of ATM. Altogether, the somatic alterations of AM may suggest potential avenues of therapeutic susceptibility.

Contemporary treatment options for advanced $B R A F$ mutant melanomas commonly involve the use of one or more small molecule tyrosine kinase inhibitors (TKI) $(28,29)$ or checkpoint immunotherapy $(30,31)$. While an attractive target, $B R A F$ mutations occur in only $15 \%$ of AM as compared to $50 \%$ of cutaneous melanomas. The presence of other therapeutically-tractable mutations such as KIT may indicate additional treatment options using other TKIs such as imatinib (32), dasatinib (33) or nilotinib (16). Aberrations in the CDK4 pathway, including amplifications of $C D K 4$ and $C C N D 1$, as well as deletions of $C D K N 2 A$, may indicate the potential utility of CDK4/6 inhibitors in AM (34-36). Interestingly, our data revealed $A T M$ deep deletions, with or without concurrent shallow deletions of RAD51 and FANCA in 3 of $8(37.5 \%)$ AM patients, supporting the use of PARP inhibitors for their treatment (37). Recent real-world data suggests that the efficacy of immune checkpoint inhibitors is significantly lower in patients with AM as compared to cutaneous melanomas (38). While the lack of high TMB may in part explain this dismal result, genetic gains of $C D K 4$ or $C C N D 1$, as well as $C D K N 2 A$ loss have been identified in melanoma patients with innate resistance to anti-PD1 checkpoint immunotherapy (39). Yu et al. have provided further evidence that this innate resistance may be mediated by the lack of IFN $\gamma$ and $\mathrm{TNF} \alpha-\mathrm{NFKB}$ signaling responses in CDK4 pathway-defective tumors, and that the addition of the CDK4/6 inhibitor palbociclib may enhance the efficacy of immunotherapy by upregulating PD-L1 (39).

Our current study is limited by the small patient cohort. Nonetheless, the results are consistent with previously published studies and lend confirmatory evidence to support a therapeutic target landscape for AM. In addition, we described the loss of genes involved in homologous recombination repair in a significant proportion of AM, supporting the use of PARP inhibitors in the treatment of 
these patients. Taken together, the recent data suggesting that complex structural alterations represent early events unique to AM pathogenesis opens up further avenues that can be exploited for therapy.

In conclusion, the genomic landscape of AM presents a unique opportunity for applying novel therapies to this group of patients. Future studies are warranted for the direct translation of these findings to the clinic.

\section{Conflicts of Interest}

The Authors have no conflicts of interest to declare in relation to this study.

\section{Authors' Contributions}

JYC analyzed the data and drafted the manuscript; CCN processed tissue and performed sequencing experiments; AHL performed the bioinformatic analyses; JYC, CEW, and JWC obtained patient samples and data; BTT, JWC designed the study; JYC, BTT, JWC interpreted the results, and revised the manuscript; JJH was responsible for the CORPG3J0151 2 grant application, sample collection, DNA preparation, clinical data confirmation, and manuscript revisions; and all authors read and approved the final version of the manuscript.

\section{Acknowledgements}

This work was supported by the Singapore Ministry of Health's National Medical Research Council under its Singapore Translational Research Investigator Award (NMRC/STAR/0006/2009), and Research Training Fellowship (NMRC/Fellowship/0054/2017), as well as SingHealth Duke-NUS Academic Medical Centre and Oncology ACP Nurturing Clinician Scientist Scheme (08FY2017/P1/14-A28), SHF-Foundation Research Grant (SHF/FG653P/2017). This work was also supported by a grant from Chang Gung Memorial Hospital (CORPG3J0151 2).

\section{References}

1 Chen YA, Teer JK, Eroglu Z, Wu JY, Koomen JM, Karreth FA, Messina JL and Smalley KSM: Translational pathology, genomics and the development of systemic therapies for acral melanoma. Semin Cancer Biol 61: 149-157, 2020. PMID: 31689494. DOI: 10.1016/j.semcancer.2019.10.017

2 Chi Z, Li S, Sheng X, Si L, Cui C, Han M and Guo J: Clinical presentation, histology, and prognoses of malignant melanoma in ethnic Chinese: a study of 522 consecutive cases. BMC Cancer 11: 85, 2011. PMID: 21349197. DOI: 10.1186/14712407-11-85

3 Shoushtari AN, Munhoz RR, Kuk D, Ott PA, Johnson DB, Tsai KK, Rapisuwon S, Eroglu Z, Sullivan RJ, Luke JJ, Gangadhar TC, Salama AK, Clark V, Burias C, Puzanov I, Atkins MB, Algazi AP, Ribas A, Wolchok JD and Postow MA: The efficacy of anti-PD-1 agents in acral and mucosal melanoma. Cancer 122: 3354-3362, 2016. PMID: 27533633. DOI: 10.1002/cncr.30259

4 Keilholz U, Ascierto PA, Dummer R, Robert C, Lorigan P, van Akkooi A, Arance A, Blank CU, Chiarion Sileni V, Donia M,
Faries MB, Gaudy-Marqueste C, Gogas H, Grob JJ, Guckenberger M, Haanen J, Hayes AJ, Hoeller C, Lebbé C, Lugowska I, Mandalà M, Márquez-Rodas I, Nathan P, Neyns B, Olofsson Bagge R, Puig S, Rutkowski P, Schilling B, Sondak VK, Tawbi H, Testori A and Michielin O: ESMO consensus conference recommendations on the management of metastatic melanoma: under the auspices of the ESMO Guidelines Committee. Ann Oncol 31: 1435-1448, 2020. PMID: 32763453. DOI: 10.1016/j.annonc.2020.07.004

5 Forschner A, Hilke FJ, Bonzheim I, Gschwind A, Demidov G, Amaral T, Ossowski S, Riess O, Schroeder C, Martus P, Klumpp B, Gonzalez-Menendez I, Garbe C, Niessner H and Sinnberg T: MDM2, MDM4 and EGFR amplifications and hyperprogression in metastatic acral and mucosal melanoma. Cancers (Basel) 12: 540, 2020. PMID: 32110946. DOI: 10.3390/cancers 12030540.

6 Lee M, Yoon J, Chung YJ, Lee SY, Choi JY, Shin OR, Park HY, Bahk WJ, Yu DS and Lee YB: Whole-exome sequencing reveals differences between nail apparatus melanoma and acral melanoma. J Am Acad Dermatol 79: 559-561.e1, 2018. PMID: 29438763. DOI: 10.1016/j.jaad.2018.02.019

7 Krauthammer M, Kong Y, Ha BH, Evans P, Bacchiocchi A, McCusker JP, Cheng E, Davis MJ, Goh G, Choi M, Ariyan S, Narayan D, Dutton-Regester K, Capatana A, Holman EC, Bosenberg M, Sznol M, Kluger HM, Brash DE, Stern DF, Materin MA, Lo RS, Mane S, Ma S, Kidd KK, Hayward NK, Lifton RP, Schlessinger J, Boggon TJ and Halaban R: Exome sequencing identifies recurrent somatic RAC1 mutations in melanoma. Nat Genet 44: 1006-1014, 2012. PMID: 22842228. DOI: $10.1038 / \mathrm{ng} .2359$

8 Newell F, Wilmott JS, Johansson PA, Nones K, Addala V, Mukhopadhyay P, Broit N, Amato CM, Van Gulick R, Kazakoff SH, Patch AM, Koufariotis LT, Lakis V, Leonard C, Wood S, Holmes O, Xu Q, Lewis K, Medina T, Gonzalez R, Saw RPM, Spillane AJ, Stretch JR, Rawson RV, Ferguson PM, Dodds TJ, Thompson JF, Long GV, Levesque MP, Robinson WA, Pearson JV, Mann GJ, Scolyer RA, Waddell N and Hayward NK: Wholegenome sequencing of acral melanoma reveals genomic complexity and diversity. Nat Commun 11: 5259, 2020. PMID: 33067454. DOI: 10.1038/s41467-020-18988-3

9 Hadi K, Yao X, Behr JM, Deshpande A, Xanthopoulakis C, Tian H, Kudman S, Rosiene J, Darmofal M, DeRose J, Mortensen R, Adney EM, Shaiber A, Gajic Z, Sigouros M, Eng K, Wala JA, Wrzeszczyński KO, Arora K, Shah M, Emde AK, Felice V, Frank MO, Darnell RB, Ghandi M, Huang F, Dewhurst S, Maciejowski J, de Lange T, Setton J, Riaz N, Reis-Filho JS, Powell S, Knowles DA, Reznik E, Mishra B, Beroukhim R, Zody MC, Robine N, Oman KM, Sanchez CA, Kuhner MK, Smith LP, Galipeau PC, Paulson TG, Reid BJ, Li X, Wilkes D, Sboner A, Mosquera JM, Elemento O and Imielinski M: Distinct classes of complex structural variation uncovered across thousands of cancer genome graphs. Cell 183: 197-210.e32, 2020. PMID: 33007263. DOI: 10.1016/j.cell.2020.08.006

10 ICGC/TCGA Pan-Cancer Analysis of Whole Genomes Consortium: Pan-cancer analysis of whole genomes. Nature 578: 82-93, 2020. PMID: 32025007. DOI: 10.1038/s41586-020-1969-6

11 Hayward NK, Wilmott JS, Waddell N, Johansson PA, Field MA, Nones K, Patch AM, Kakavand H, Alexandrov LB, Burke H, Jakrot V, Kazakoff S, Holmes O, Leonard C, Sabarinathan R, Mularoni L, Wood S, Xu Q, Waddell N, Tembe V, Pupo GM, De Paoli-Iseppi R, Vilain RE, Shang P, Lau LMS, Dagg RA, 
Schramm SJ, Pritchard A, Dutton-Regester K, Newell F, Fitzgerald A, Shang CA, Grimmond SM, Pickett HA, Yang JY, Stretch JR, Behren A, Kefford RF, Hersey P, Long GV, Cebon J, Shackleton M, Spillane AJ, Saw RPM, López-Bigas N, Pearson JV, Thompson JF, Scolyer RA and Mann GJ: Wholegenome landscapes of major melanoma subtypes. Nature 545: 175-180, 2017. PMID: 28467829. DOI: 10.1038/nature22071

12 Liang WS, Hendricks W, Kiefer J, Schmidt J, Sekar S, Carpten J, Craig DW, Adkins J, Cuyugan L, Manojlovic Z, Halperin RF, Helland A, Nasser S, Legendre C, Hurley LH, Sivaprakasam K, Johnson DB, Crandall H, Busam KJ, Zismann V, Deluca V, Lee $\mathrm{J}$, Sekulic A, Ariyan CE, Sosman J and Trent J: Integrated genomic analyses reveal frequent TERT aberrations in acral melanoma. Genome Res 27: 524-532, 2017. PMID: 28373299. DOI: $10.1101 / \mathrm{gr} .213348 .116$

13 Rawson RV, Johansson PA, Hayward NK, Waddell N, Patch AM, Lo S, Pearson JV, Thompson JF, Mann GJ, Scolyer RA and Wilmott JS: Unexpected UVR and non-UVR mutation burden in some acral and cutaneous melanomas. Lab Invest 97: 130-145, 2017. PMID: 28067894. DOI: 10.1038/labinvest.2016.143

14 Furney SJ, Turajlic S, Stamp G, Thomas JM, Hayes A, Strauss D, Gavrielides M, Xing W, Gore M, Larkin J and Marais R: The mutational burden of acral melanoma revealed by whole-genome sequencing and comparative analysis. Pigment Cell Melanoma Res 27: 835-838, 2014. PMID: 24913711. DOI: 10.1111/pcmr.12279

15 Hodi FS, Corless CL, Giobbie-Hurder A, Fletcher JA, Zhu M, Marino-Enriquez A, Friedlander P, Gonzalez R, Weber JS, Gajewski TF, O'Day SJ, Kim KB, Lawrence D, Flaherty KT, Luke JJ, Collichio FA, Ernstoff MS, Heinrich MC, Beadling C, Zukotynski KA, Yap JT, Van den Abbeele AD, Demetri GD and Fisher DE: Imatinib for melanomas harboring mutationally activated or amplified KIT arising on mucosal, acral, and chronically sun-damaged skin. J Clin Oncol 31: 3182-3190, 2013. PMID: 23775962. DOI: $10.1200 / J C O .2012 .47 .7836$

16 Guo J, Carvajal RD, Dummer R, Hauschild A, Daud A, Bastian BC, Markovic SN, Queirolo P, Arance A, Berking C, Camargo V, Herchenhorn D, Petrella TM, Schadendorf D, Sharfman W, Testori A, Novick S, Hertle S, Nourry C, Chen Q and Hodi FS: Efficacy and safety of nilotinib in patients with KIT-mutated metastatic or inoperable melanoma: final results from the global, single-arm, phase II TEAM trial. Ann Oncol 28: 1380-1387, 2017. PMID: 28327988. DOI: 10.1093/annonc/mdx079

17 Carvajal RD, Lawrence DP, Weber JS, Gajewski TF, Gonzalez R, Lutzky J, O'Day SJ, Hamid O, Wolchok JD, Chapman PB, Sullivan RJ, Teitcher JB, Ramaiya N, Giobbie-Hurder A, Antonescu CR, Heinrich MC, Bastian BC, Corless CL, Fletcher JA and Hodi FS: Phase II study of nilotinib in melanoma harboring KIT alterations following progression to prior KIT inhibition. Clin Cancer Res 21: 2289-2296, 2015. PMID: 25695690. DOI: 10.1158/1078-0432.CCR-14-1630

18 Kalinsky K, Lee S, Rubin KM, Lawrence DP, Iafrarte AJ, Borger DR, Margolin KA, Leitao MM Jr, Tarhini AA, Koon HB, Pecora AL, Jaslowski AJ, Cohen GI, Kuzel TM, Lao CD and Kirkwood JM: A phase 2 trial of dasatinib in patients with locally advanced or stage IV mucosal, acral, or vulvovaginal melanoma: A trial of the ECOG-ACRIN Cancer Research Group (E2607). Cancer 123: 2688-2697, 2017. PMID: 28334439. DOI: 10.1002/cncr.30663

19 Mao L, Cao Y, Sheng X, Bai X, Chi Z, Cui C, Wang X, Tang B, Lian B, Yan X, Li S, Zhou L, Wei X, Li X, Qi ZH, Si L and Guo $\mathrm{J}$ : Palbociclib $(\mathrm{P})$ in advanced acral lentiginous melanoma
(ALM) with CDK4 pathway gene aberrations. J Clin Oncol 37: 9528-9528, 2019. DOI: 10.1200/JCO.2019.37.15_supp1.9528

20 Balch CM, Gershenwald JE, Soong SJ, Thompson JF, Atkins MB, Byrd DR, Buzaid AC, Cochran AJ, Coit DG, Ding S, Eggermont AM, Flaherty KT, Gimotty PA, Kirkwood JM, McMasters KM, Mihm MC Jr, Morton DL, Ross MI, Sober AJ and Sondak VK: Final version of 2009 AJCC melanoma staging and classification. J Clin Oncol 27: 6199-6206, 2009. PMID: 19917835. DOI: $10.1200 / J C O .2009 .23 .4799$

$21 \mathrm{Li} \mathrm{H}$ and Durbin R: Fast and accurate short read alignment with Burrows-Wheeler transform. Bioinformatics 25: 1754-1760, 2009. PMID: 19451168. DOI: 10.1093/bioinformatics/btp324

22 McKenna A, Hanna M, Banks E, Sivachenko A, Cibulskis K, Kernytsky A, Garimella K, Altshuler D, Gabriel S, Daly M and DePristo MA: The Genome Analysis Toolkit: a MapReduce framework for analyzing next-generation DNA sequencing data. Genome Res 20: 1297-1303, 2010. PMID: 20644199. DOI: 10.1101/gr.107524.110

23 McLaren W, Gil L, Hunt SE, Riat HS, Ritchie GR, Thormann A, Flicek P and Cunningham F: The Ensembl variant effect predictor. Genome Biol 17: 122, 2016. PMID: 27268795. DOI: 10.1186/s13059-016-0974-4

24 Alexandrov LB, Kim J, Haradhvala NJ, Huang MN, Tian Ng AW, Wu Y, Boot A, Covington KR, Gordenin DA, Bergstrom EN, Islam SMA, Lopez-Bigas N, Klimczak LJ, McPherson JR, Morganella S, Sabarinathan R, Wheeler DA, Mustonen V, PCAWG Mutational Signatures Working Group, Getz G, Rozen SG, Stratton MR and PCAWG Consortium: The repertoire of mutational signatures in human cancer. Nature 578: 94-101, 2020. PMID: 32025018. DOI: 10.1038/s41586-020-1943-3

25 Mermel CH, Schumacher SE, Hill B, Meyerson ML, Beroukhim $\mathrm{R}$ and Getz G: GISTIC2.0 facilitates sensitive and confident localization of the targets of focal somatic copy-number alteration in human cancers. Genome Biol 12: R41, 2011. PMID: 21527027. DOI: $10.1186 / \mathrm{gb}-2011-12-4-\mathrm{r} 41$

26 Ha G, Roth A, Khattra J, Ho J, Yap D, Prentice LM, Melnyk N, McPherson A, Bashashati A, Laks E, Biele J, Ding J, Le A, Rosner J, Shumansky K, Marra MA, Gilks CB, Huntsman DG, McAlpine JN, Aparicio S and Shah SP: TITAN: inference of copy number architectures in clonal cell populations from tumor whole-genome sequence data. Genome Res 24: 1881-1893, 2014. PMID: 25060187. DOI: 10.1101/gr.180281

27 Noujaim J, Gonzalez D, Thway K, Jones RL and Judson I: p.(L576P) -KIT mutation in GIST: Favorable prognosis and sensitive to imatinib? Cancer Biol Ther 17: 543-545, 2016. PMID: 26942271. DOI: 10.1080/15384047.2016.1156263

28 Long GV, Stroyakovskiy D, Gogas H, Levchenko E, de Braud F, Larkin J, Garbe C, Jouary T, Hauschild A, Grob JJ, Chiarion Sileni V, Lebbe C, Mandalà M, Millward M, Arance A, Bondarenko I, Haanen JB, Hansson J, Utikal J, Ferraresi V, Kovalenko N, Mohr P, Probachai V, Schadendorf D, Nathan P, Robert C, Ribas A, DeMarini DJ, Irani JG, Casey M, Ouellet D, Martin AM, Le N, Patel K and Flaherty K: Combined BRAF and MEK inhibition versus BRAF inhibition alone in melanoma. $\mathrm{N}$ Engl J Med 371: 1877-1888, 2014. PMID: 25265492. DOI: 10.1056/NEJMoa1406037

29 Larkin J, Ascierto PA, Dréno B, Atkinson V, Liszkay G, Maio M, Mandalà M, Demidov L, Stroyakovskiy D, Thomas L, de la Cruz-Merino L, Dutriaux C, Garbe C, Sovak MA, Chang I, Choong N, Hack SP, McArthur GA and Ribas A: Combined 
vemurafenib and cobimetinib in BRAF-mutated melanoma. N Engl J Med 371: 1867-1876, 2014. PMID: 25265494. DOI: 10.1056/NEJMoa1408868

30 Robert C, Schachter J, Long GV, Arance A, Grob JJ, Mortier L, Daud A, Carlino MS, McNeil C, Lotem M, Larkin J, Lorigan P, Neyns B, Blank CU, Hamid O, Mateus C, Shapira-Frommer R, Kosh M, Zhou H, Ibrahim N, Ebbinghaus S, Ribas A and KEYNOTE-006 investigators: Pembrolizumab versus ipilimumab in advanced melanoma. N Engl J Med 372: 25212532, 2015. PMID: 25891173. DOI: 10.1056/NEJMoa1503093

31 Larkin J, Chiarion-Sileni V, Gonzalez R, Grob JJ, Rutkowski P, Lao CD, Cowey CL, Schadendorf D, Wagstaff J, Dummer R, Ferrucci PF, Smylie M, Hogg D, Hill A, Márquez-Rodas I, Haanen J, Guidoboni M, Maio M, Schöffski P, Carlino MS, Lebbé C, McArthur G, Ascierto PA, Daniels GA, Long GV, Bastholt L, Rizzo JI, Balogh A, Moshyk A, Hodi FS and Wolchok JD: Five-year survival with combined nivolumab and ipilimumab in advanced melanoma. N Engl J Med 381: 15351546, 2019. PMID: 31562797 . DOI: 10.1056/NEJMoa1910836

32 Carvajal RD, Antonescu CR, Wolchok JD, Chapman PB, Roman RA, Teitcher J, Panageas KS, Busam KJ, Chmielowski B, Lutzky J, Pavlick AC, Fusco A, Cane L, Takebe N, Vemula S, Bouvier N, Bastian BC and Schwartz GK: KIT as a therapeutic target in metastatic melanoma. JAMA 305: 2327-2334, 2011. PMID: 21642685. DOI: 10.1001/jama.2011.746

33 Woodman SE, Trent JC, Stemke-Hale K, Lazar AJ, Pricl S, Pavan GM, Fermeglia M, Gopal YN, Yang D, Podoloff DA, Ivan D, Kim KB, Papadopoulos N, Hwu P, Mills GB and Davies MA: Activity of dasatinib against L576P KIT mutant melanoma: molecular, cellular, and clinical correlates. Mol Cancer Ther 8: 2079-2085, 2009. PMID: 19671763. DOI: 10.1158/15357163.MCT-09-0459

34 Kong Y, Sheng X, Wu X, Yan J, Ma M, Yu J, Si L, Chi Z, Cui C, Dai J, Li Y, Yu H, Xu T, Tang H, Tang B, Mao L, Lian B, Wang X, Yan X, Li S and Guo J: Frequent genetic aberrations in the CDK4 pathway in acral melanoma indicate the potential for CDK4/6 inhibitors in targeted therapy. Clin Cancer Res 23: 6946-6957, 2017. PMID: 28830923. DOI: 10.1158/10780432.CCR-17-0070

35 Tang B, Sheng X, Kong Y, Chi Z, Si L, Cui C, Yan X, Mao L, Lian B, Li S, Wang X, Dai J, Bai X, Zhou L and Guo J: Palbociclib for treatment of metastatic melanoma with copy number variations of CDK4 pathway: case report. Chin Clin Oncol 7: 62, 2018. PMID: 30180747. DOI: $10.21037 /$ cco.2018.06.08
36 Young RJ, Waldeck K, Martin C, Foo JH, Cameron DP, Kirby L, Do H, Mitchell C, Cullinane C, Liu W, Fox SB, DuttonRegester K, Hayward NK, Jene N, Dobrovic A, Pearson RB, Christensen JG, Randolph S, McArthur GA and Sheppard KE: Loss of CDKN2A expression is a frequent event in primary invasive melanoma and correlates with sensitivity to the CDK4/6 inhibitor PD0332991 in melanoma cell lines. Pigment Cell Melanoma Res 27: 590-600, 2014. PMID: 24495407. DOI: 10.1111/pcmr.12228

37 Mateo J, Carreira S, Sandhu S, Miranda S, Mossop H, PerezLopez R, Nava Rodrigues D, Robinson D, Omlin A, Tunariu N, Boysen G, Porta N, Flohr P, Gillman A, Figueiredo I, Paulding C, Seed G, Jain S, Ralph C, Protheroe A, Hussain S, Jones R, Elliott T, McGovern U, Bianchini D, Goodall J, Zafeiriou Z, Williamson CT, Ferraldeschi R, Riisnaes R, Ebbs B, Fowler G, Roda D, Yuan W, Wu YM, Cao X, Brough R, Pemberton H, A'Hern R, Swain A, Kunju LP, Eeles R, Attard G, Lord CJ, Ashworth A, Rubin MA, Knudsen KE, Feng FY, Chinnaiyan AM, Hall E and de Bono JS: DNA-repair defects and olaparib in metastatic prostate cancer. N Engl J Med 373: 1697-1708, 2015. PMID: 26510020. DOI: 10.1056/NEJMoa1506859

38 Nakamura Y, Namikawa K, Yoshino K, Yoshikawa S, Uchi H, Goto K, Nakamura Y, Fukushima S, Kiniwa Y, Takenouchi T, Uhara H, Kawai T, Hatta N, Funakoshi T, Teramoto Y, Otsuka A, Doi H, Ogata D, Matsushita S, Isei T, Hayashi T, Shibayama $\mathrm{Y}$ and Yamazaki N: Anti-PD1 checkpoint inhibitor therapy in acral melanoma: a multicenter study of 193 Japanese patients. Ann Oncol 31: 1198-1206, 2020. PMID: 32522691. DOI: 10.1016/j.annonc.2020.05.031

39 Yu J, Yan J, Guo Q, Chi Z, Tang B, Zheng B, Yu J, Yin T, Cheng Z, Wu X, Yu H, Dai J, Sheng X, Si L, Cui C, Bai X, Mao L, Lian B, Wang X, Yan X, Li S, Zhou L, Flaherty KT, Guo J and Kong Y: Genetic aberrations in the CDK4 pathway are associated with innate resistance to PD-1 blockade in Chinese patients with non-cutaneous melanoma. Clin Cancer Res 25: 6511-6523, 2019. PMID: 31375512. DOI: 10.1158/10780432.CCR-19-0475
Received December 14, 2020

Revised December 29, 2020

Accepted December 30, 2020 